\title{
Molecular evidence for non-penetrance in Best's disease
}

\author{
Bernhard H F Weber, Diane Walker, Bertram Müller
}

\begin{abstract}
The present study provides evidence for a possible case of non-penetrance in Best's disease. We have analysed the at risk members of a three generation family with an established history of Best's disease by ophthalmoscopic examination, electrophysiological tests, and genetic analysis. The clinical examination identified 10 affected and five unaffected persons in this family. Genetic linkage analysis strongly supports linkage of the disease locus to DNA microsatellite markers from proximal 11q. The genotyping data were used to construct the familial haplotype associated with Best's disease. One person was identified who has inherited the Best's disease haplotype from his affected mother. Fundus examination and electrophysiological tests have repeatedly been performed in this patient but failed to show any signs of the disease. Based on these findings we have jointly estimated the most likely order of the Best's disease locus relative to the closest flanking markers at various penetrance values. A maximum likelihood estimate for the heterozygote penetrance was reached for the locus order D11S903Best's disease-PYGM at a penetrance value of 0.96 .
\end{abstract}

( $(\mathcal{H}$ Med Genet 1994;31:388-392)

Best's disease (BD) (vitelliform macular dystrophy, MIM No 153700) is an autosomal dominantly inherited macular degeneration with juvenile onset. ${ }^{1}$ The early fundus picture consists of a well demarcated, subretinal lesion that classically resembles an egg yolk. The visual acuity at this stage is often normal. With time, the egg yolk-like material undergoes several changes. Initially, disruption of the "egg yolk" results in a pseudohypopyon stage. Forming a fluid level, the yellowish material

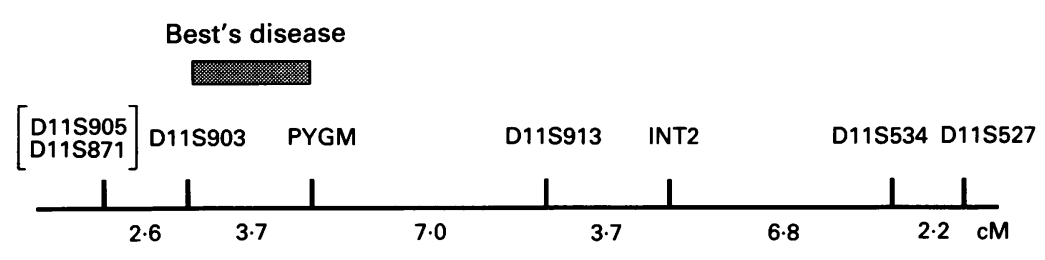

$\leftarrow$ 11pter

Figure 1 Localisation of the Best's disease locus relative to loci from proximal 11q. Microsatellite markers from these loci have been used for the genotyping of the family (fig 2). The data are taken from Weber et al. ${ }^{13}$ appears to shift with gravity in the subretinal space. Further disruption results in multiple, irregular yellow clumps which resemble scrambled egg. At this stage, the vision is moderately impaired. Eventually, the yellow material disappears and subretinal scars and choroidal neovascularisation may develop, severely impairing vision. Histopathology of the "scrambled egg" stage of the disease suggests that $\mathrm{BD}$ is a generalised disorder of the retinal pigment epithelium (RPE) that is associated with the abnormal accumulation of yellowish material (lipofuscin) in the RPE and the subretinal space. ${ }^{2}$ Variable expressivity of the disease, even between each eye of an affected person, has often been noted. ${ }^{3-6}$ Many affected persons never show fundus abnormalities and are diagnosed as asymptomatic carriers by electro-oculography (EOG) ${ }^{78} \mathrm{An}$ EOG measures the standing potential that exists between the cornea and the retina which is primarily generated by the retinal pigment epithelium. ${ }^{9}$ An abnormally low EOG ratio comparing the potentials recorded in the light and dark adapted state has been accepted as a characteristic electrophysiological sign of Best's disease. ${ }^{1011}$

Essentially, it is the availability of the EOG test that has led to the assumption that the penetrance in Best's disease is complete. In fact, no case of incomplete penetrance has been reported to date. More recently, the defective gene causing Best's disease has been mapped genetically to the proximal long arm of chromosome 11 by showing linkage between the $\mathrm{BD}$ locus and several (CA) dinucleotide markers from the region. ${ }^{612}$ Subsequently, the localisation of the Best's disease gene in proximal $11 \mathrm{q}$ has been refined to a $3.7 \mathrm{cM}$ interval between the markers at D11S903 and PYGM ${ }^{13}$ (fig 1).

We have now identified a 37 year old male from a three generation Best's disease family who has inherited the BD haplotype from his affected mother. Repeated examination and EOG testing have not indicated any signs of Best's disease in this person. To our knowledge, this case is the first documented example of non-penetrance in Best's disease. Based on our results we have estimated the maximum likelihood for the heterozygote penetrance at a value of 0.96 .

\section{Case report}

Subject III.14 was born in 1955 as the first of two children. He was at $50 \%$ risk of inheriting the Best's disease gene from his affected mother, II.3 (fig 2). He developed insulin dependent diabetes mellitus in 1978. He was 
I

II

III D118071

III D118006

IV

D118903
PYGI
D118913
INTT
D118534

D118534
D118527

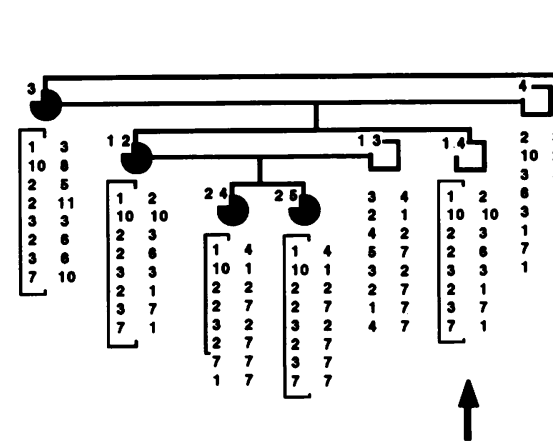

$17 T^{2} 8$

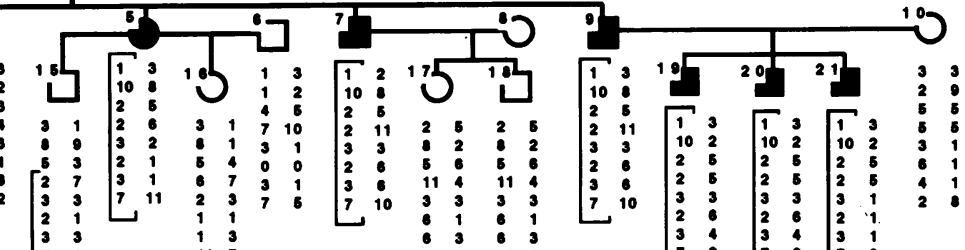

Figure 2 Pedigree of the family. Constructed haplotypes are indicated. The haplotype associated with Best's disease is in brackets. The unaffected person III.14 has inherited the BD haplotype from his affected mother (arrow).

first examined in 1987 when his family was being recruited for pedigree analysis of Best's disease. At that time his vision was correctable to 6/6 OU with a moderate myopic correction. His intraocular pressures were normal. Electrodiagnostic studies were performed. The EOG light/dark ratios were normal at $2 \cdot 1 \mathrm{RE}$ and 1.9 LE (fig 3, table 1). Colour vision testing with the Farnsworth Munsell 100 Hue Test was slightly abnormal with a predominantly yellow/blue error and with an error score of $128 \mathrm{RE}$ and $160 \mathrm{LE}$ (normal < 120). The photopic and scotopic ERG, $30 \mathrm{~Hz}$ flicker, and oscillatory potentials were normal.

III.14 was last examined in 1993. At that time his vision was correctable to $/ 6 \mathrm{RE}$ and $/ 6$ LE. The anterior segment examination and intraocular pressures were normal. The fundus examination showed the presence of a mild, non-proliferative diabetic retinopathy. The EOG was also repeated (fig 3). Excellent

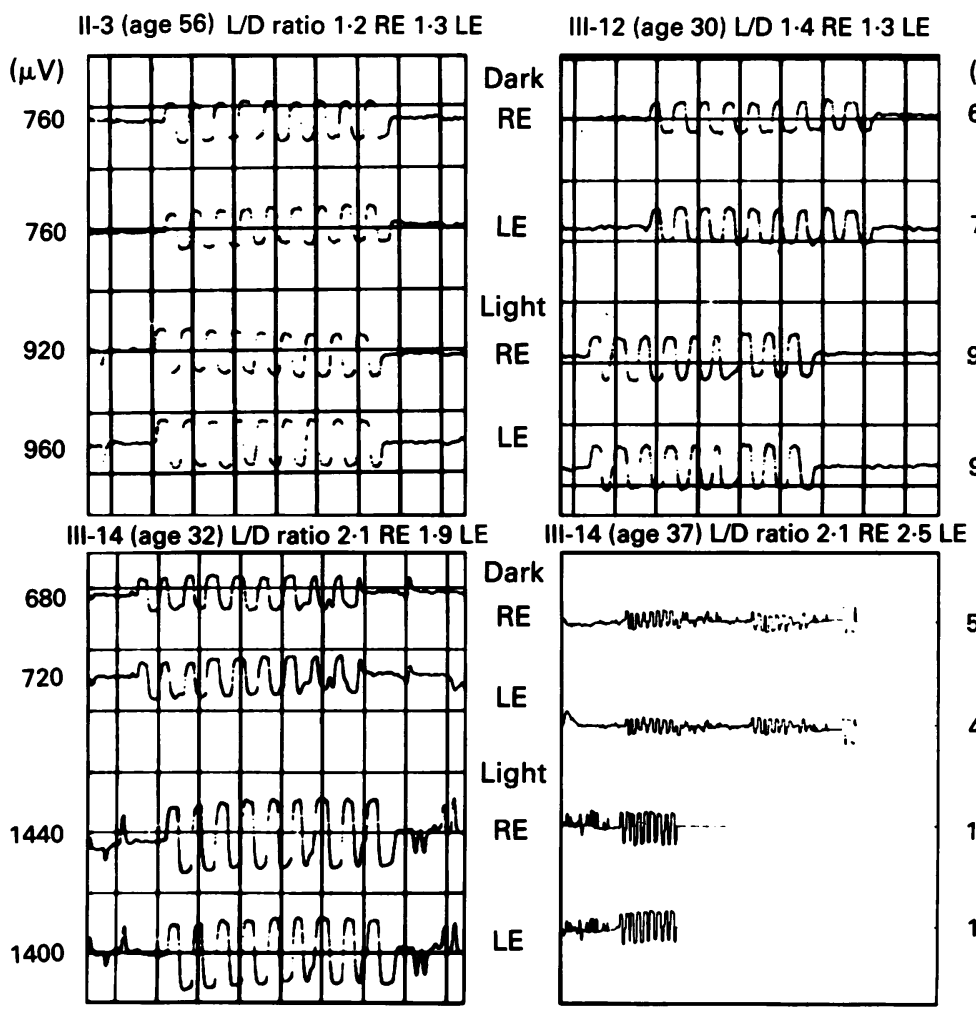

Figure 3 EOG tracings from III.14 aged 32 and 37 (bottom), his mother (II.3) (upper left), and his sister (III.12) (upper right). Only the lowest dark peak and the highest light peak recordings are shown for the right (RE) and the left ( $L E)$ eye, respectively. recordings were obtained. The minimum dark response and the maximum light response were used to calculate the light/dark ratios of 2.1 RE and 2.5 LE (fig 3, table 1).

\section{Family history}

The mother (II.3) of subject III.14 (fig 2) was started on Timoptic $0.25 \%$ eye drops in the left eye in 1986 because of raised intraocular pressure (IOP) $(23 \mathrm{~mm} \mathrm{Hg} \mathrm{RE}$ and $28 \mathrm{~mm} \mathrm{Hg}$ LE). Her $1 O P$ is now controlled at $17 \mathrm{~mm} \mathrm{Hg}$ in both eyes. On her latest examination in 1987 the vision was correctable to $20 / 40$ in both eyes with +1.00 spherical lens. Excellent ERG recordings were obtained. The $30 \mathrm{~Hz}$ flicker and oscillatory potentials were normal. The FM 100 hue scores in the colour vision test were slightly abnormal at $164 \mathrm{RE}$ and $196 \mathrm{LE}$. Fundus examination showed "egg yolk" lesions in both macula, typical of Best's disease. EOG light/dark ratios were definitely subnormal at 1.2 LE and 1.3 RE (fig 3, table 1) and support the diagnosis of Best's disease.

ERG recordings of III.12 (daughter of II.3) were obtained in both light and dark adaption; $30 \mathrm{~Hz}$ flicker and oscillatory potentials were normal. Scores on the FM 100 hue test were in the normal range (76 RE and $96 \mathrm{LE}$ ). Fundus examinations were normal. The EOG light/ dark ratios were definitely subnormal bilaterally (1.4 RE and 1.3 LE) (fig 3, table 1).

Extended pedigree analysis has identified an additional eight members of family $\mathrm{N}$ with distinctly subnormal EOG light/dark ratios of 1.4 or less (table 1). Except for II.9 (brother of II.3), whose fundus examination showed macular scars in both eyes, all other persons with depressed EOG ratios showed normal fundi (table 1).

In summary, the mode of inheritance, the ophthalmoscopic examinations, and the electrodiagnostic tests strongly support the diagnosis of Best's disease with juvenile onset in the family.

\section{Materials and methods} CLINICAL EXAMINATION AND ELECTRODIAGNOSTIC TESTS

The clinical and electrodiagnostic tests were performed at the Eye Care Center, Vancouver, Canada (Department of Ophthalmology, UBC). Subject III.14 was also seen by one of 
Table 1 EOG data and fundus appearances of at risk persons in the family

\begin{tabular}{|c|c|c|c|c|}
\hline Subject* & $\begin{array}{l}\text { Age at } \\
\text { examination }(y)\end{array}$ & Fundus appearance & $\begin{array}{l}E O G L / D \text { ratio: } \\
R E, L E\end{array}$ & Diagnosis \\
\hline II. 3 & 56 & $\begin{array}{l}\text { "Egg yolk" lesions in } \\
\text { both macula }\end{array}$ & $1 \cdot 2,1 \cdot 3$ & Best's disease \\
\hline II. 5 & 58 & Normal & $1.4,1.3$ & Best's disease \\
\hline II. 7 & 46 & Normal & $1 \cdot 3,1 \cdot 4$ & Best's disease \\
\hline II. 9 & 49 & Macular scars & ND & Best's disease \\
\hline III. 12 & 30 & Normal & $1.4,1.3$ & Best's disease \\
\hline III.14 & 32 & Normal & $2 \cdot 1,1 \cdot 9$ & Unaffected \\
\hline III.14 & 37 & Normal & $2 \cdot 1,2 \cdot 5$ & Unaffected \\
\hline III. 15 & 33 & Normal & $2 \cdot 2,2 \cdot 3$ & Unaffected \\
\hline III.16 & 19 & Normal & $1.9,2.5$ & Unaffected \\
\hline III. 17 & 9 & Normal & $1 \cdot 9,2 \cdot 1$ & Unaffected \\
\hline III. 18 & 12 & Normal & $2 \cdot 4,2 \cdot 2$ & Unaffected \\
\hline III. 19 & 32 & Normal & $1 \cdot 3,1 \cdot 4$ & Best's disease \\
\hline III. 20 & 27 & Normal & $1.5,1.5$ & Best's disease \\
\hline III. 21 & 26 & Normal & $1 \cdot 3,1 \cdot 3$ & Best's disease \\
\hline IV. 24 & 11 & Normal & $1 \cdot 6,1 \cdot 6$ & No diagnosis $\dagger$ \\
\hline IV. 25 & 9 & Normal & $1 \cdot 4,1.3$ & Best's disease \\
\hline
\end{tabular}

* Same pedigree numbers as fig 2 .

+ Poor quality EOG tracing.

$\mathrm{ND}=$ not done. the authors (DW). Ganzfeld ERGs were recorded using the international standard for electroretinography. ${ }^{14}$ Colour vision testing was done using the Farnsworth-Munsell 100 Hue Test (Munsell Colour Co, Baltimore, MD, USA). The EOG was performed using a modified Arden technique. ${ }^{15}$ The pupil was not dilated. A Ganzfeld adaption luminance of 118 foot-lamberts $\left(405 \mathrm{~cd} / \mathrm{m}^{2}\right)$ was used. Horizontal sweeps at a rate of 18 per minute over an excursion of 30 degrees were recorded by skin electrodes. Sample recordings under light and dark adapted conditions were done for 15 minutes each at one minute intervals. ${ }^{16}$

\section{DNA AND STATISTICAL ANALYSIS}

DNA was isolated from peripheral blood and sputum samples using standard extraction methods. ${ }^{17}$ DNA from fingernail clippings was extracted as previously described. ${ }^{18}$ Microsatellite markers were selected from published reports as follows: (D11S905, D11S903, D11S913), ${ }^{19}$ D11S871 (GDB, Johns Hopkins University, Baltimore, MA), D11S534, ${ }^{20}$ D11S527, ${ }^{21}$ INT2, ${ }^{22}$ PYGM. ${ }^{23}$ Amplifications of the microsatellite repeats were achieved by the polymerase chain reaction (PCR) in the presence of ${ }^{32} \mathrm{P}$-dCTP using conditions as given in the references for each microsatellite marker. Reaction products were electrophoretically separated on a $6 \%$ sequencing polyacrylamide gel, followed by drying and autoradiography.

Two point analysis and likelihood calculations were performed using the MLINK and ILINK routines of the LINKAGE program package version $5 \cdot 1$, respectively. ${ }^{24}$ The allele

Table 2 Two point lod scores between BD and markers in proximal 11q

\begin{tabular}{llllllllll}
\hline & \multicolumn{1}{l}{ Lod score $(Z)$ at $\theta$ of* } \\
\cline { 2 - 9 } & 0 & 0.01 & 0.05 & 0.1 & 0.2 & 0.3 & 0.4 & $\theta$ max & $Z$ max \\
\hline D11S905 & 2.09 & 2.13 & 2.15 & 2.04 & 1.62 & 1.04 & 0.38 & 0.036 & 2.16 \\
D11S871 & 1.22 & 1.27 & 1.35 & 1.32 & 1.07 & 0.71 & 0.3 & 0.058 & 1.36 \\
D11S903 & 1.66 & 1.7 & 1.77 & 1.71 & 1.4 & 0.95 & 0.41 & 0.051 & 1.77 \\
PYGM & 0.95 & 1.08 & 1.34 & 1.41 & 1.22 & 0.82 & 0.34 & 0.098 & 1.41 \\
D11S913 & -1.06 & -0.93 & -0.6 & -0.37 & -0.14 & -0.04 & -0.01 & 0.501 & 0 \\
INT2 & 1.38 & 1.43 & 1.5 & 1.46 & 1.19 & 0.8 & 0.34 & 0.056 & 1.49 \\
D11S534 & -5.91 & -2 & -0.84 & -0.3 & 0.09 & 0.14 & 0.06 & 0.279 & 0.15 \\
D11S527 & -4.61 & -0.8 & 0.19 & 0.58 & 0.73 & 0.53 & 0.18 & 0.181 & 0.74 \\
\hline
\end{tabular}

* Based on genotyping data from fig 2 . systems were reduced to four or five alleles per marker to facilitate computational analysis.

\section{Results}

MOLECULAR ANALYSIS

All relevant members of family $\mathrm{N}$ were genotyped with eight highly polymorphic microsatellite markers from proximal 11q (fig 2). The relative order, the genetic distances, and the localisation of the Best's disease locus relative to these markers have been determined previously ${ }^{13}$ and are schematically summarised in fig 1.

Using the genotyping data, the haplotypes for each family member were constructed spanning an approximately $26 \mathrm{cM}$ interval between the flanking markers at [D11S905, D11S871] and D11S527 (fig 2). All affected subjects share an identical haplotype (bracketed haplotypes in fig 2). Two recombination events involving the affected haplotype have to be assumed. The unaffected person III.15 has inherited the unaffected haplotype from [D11S905, D11S871] to DIIS903 and the affected haplotype from PYGM to D11S527, suggesting a crossing over between D11S903 and PYGM. A second crossing over between markers at INT2 and D11S534 should have occurred in the affected person IV.24. Both recombinants are consistent with the previously determined location of the Best's disease locus between D11S903 and PYGM (fig 1). Sibs III.12 and III.14 both inherited the haplotype associated with Best's disease from their affected mother. In order to exclude possible sample mix ups or typing errors the genetic analysis in subjects II.3, III.12, and III.14 was repeated with independently isolated lymphocyte DNA samples. The results were identical with the previous typings (data not shown). In addition, the genotypings in subject III.14 were confirmed independently with DNA samples isolated from fingernail clippings and sputum (data not shown).

\section{STATISTICAL ANALYSIS}

Two point maximum likelihood calculations using the genotyping data from our family are highly suggestive of linkage between the Best's disease locus and the markers used in this study. A maximum lod score of $2 \cdot 16$ at a recombination frequency of $3.6 \%$ was reached for locus D11 S905 (table 2). For these calculations the status of subject III.14 was assumed to be unaffected and the penetrance value was lowered to 0.96 (see below).

Faced with the findings in subject III.14, we decided to test the hypothesis of reduced penetrance versus complete penetrance in Best's disease by using a likelihood ratio test. The likelihoods were estimated using the ILINK routine of the LINKAGE program. ${ }^{24}$ For the calculations, a larger data set with genotyping results from 98 members from three Best's disease families including the family presented in this study were used. ${ }^{13}$ This included a total of 39 affected and 30 unaffected persons who were a priori at risk of carrying the Best's 
Table 3 Maximum likelihood estimates with respect to locus order and penetrance

\begin{tabular}{lll}
\hline Penetrance & Order of loci & $-2 \ln L+$ constant $^{*}$ \\
\hline 1.00 & BD-B11S903-PYGM & 696.23 \\
0.99 & D11S903-BD-PYGM & 693.14 \\
0.98 & D11S903-BD-PYGM & 691.98 \\
0.97 & D11S903-BD-PYGM & 691.45 \\
0.96 & D11S903-BD-PYGM & $691.23 \dagger$ \\
0.95 & D11S903-BD-PYGM & 691.49 \\
0.90 & D11S903-BD-PYGM & 693.05 \\
0.85 & D11S903-BD-PYGM & 695.82 \\
0.80 & D11S903-BD-PYGM & 698.92 \\
0.75 & D11S903-BD-PYGM & 703.34 \\
\hline
\end{tabular}

* Denotes -2 times the natural logarithm of the likelihood of a given order and penetrance plus an arbitrary constant. $\dagger$ Difference from penetrance value of 1 significant at the $5 \%$ level.

disease gene. Subject III.14 was assumed to be unaffected.

We maximised the likelihood in all three pedigrees with respect to locus order and penetrance (table 3 ). The highest $-21 \mathrm{~nL}+$ constant was reached for the order D11S903Best's disease-PYGM at a penetrance value of $0.96(-21 \mathrm{~nL}+$ constant $=691 \cdot 23)$. The highest $-2 \operatorname{lnL}+$ constant at a fixed penetrance value of 1 was obtained for the order Best's disease-D11S903-PYGM $(-21 \mathrm{~nL}+$ constant $=$ 696.23). This difference is significant at the $5 \%$ level $\left(\chi^{2}=5 \cdot 00,1 \mathrm{df}\right)$.

\section{Discussion}

In Best's disease a wide range in the expressivity of the defective gene has often been reported $^{35}$ and is also evident in the family presented in this study. While two members of the family show fundus lesions characteristic of Best's disease, another eight asymptomatic persons were diagnosed as carriers of the disease gene based on electro-oculography (EOG). A subnormal and prolonged light rise of the EOG has repeatedly been found to be highly characteristic of Best's disease. ${ }^{781025}$ Taken together, the results from the clinical examinations and the electrophysiological tests clearly confirm the diagnosis of Best's disease in our family.

We have now identified one person in this pedigree who represents the first documented case of non-penetrance in Best's disease. Genetic analysis has shown that sib III.14 has inherited the Best's disease haplotype. On the other hand, fundus examinations and repeated EOG tests have not indicated any signs of the disease. By repeating the EOG test we have excluded the possibility that poor quality tracings or other factors might have influenced the diagnosis previously. In addition, the two recordings clearly document that no changes have occurred in the EOG tracings over the last five years. In Best's disease, it is generally accepted that the EOG abnormalities are evident in the first decade of life and only the time consuming recording procedure itself seems to be a major hindrance for obtaining good quality EOG tracings from very young patients. At his last EOG test III.14 was 37 years of age. To our knowledge, there are no published cases with onset of the EOG abnormalities in the third or fourth decade of life.

Interestingly, III.14 and his affected mother both had slightly abnormal colour vision. It could be argued that this abnormality represents a clinical manifestation of affectedness in our family. However, colour vision in the affected sister of III.14 is in the normal range. In addition, colour defects in Best's disease patients are generally proportional to the degree of visual loss and have, to our knowledge, never been reported in unaffected carriers. It, therefore, appears highly questionable whether the colour vision defect in our family is causally linked to the Best's disease locus. More likely, this defect might segregate as an independent trait in the family.

The evidence for non-penetrance in our study is based on genetic analysis and relies upon the fact that in our family the Best's disease locus is linked to proximal 11q. In many hereditary retinal degeneration disorders genetic heterogeneity seems to be a common phenomenon, for example, autosomal dominant retinitis pigmentosa. ${ }^{26-28}$ Genetic heterogeneity may also be frequent in macular dystrophies. ${ }^{29} 30$ However, in contrast to the findings in other retinopathies, the genetic data from several Best's disease studies suggest only one location of the defective gene in proximal $11 \mathrm{q}^{6}{ }^{612} \mathrm{In}$ order to test for linkage of the Best's disease locus to proximal 11q markers in our family we have performed a two point linkage analysis. The results are highly suggestive of linkage although statistically not significant.

The possibility of a double crossing over between markers at D11S903 and PYGM should also be considered. In this case III.14 would carry the normal gene on the Best's disease haplotype. However, this possibility has been refuted by the likelihood ratio test. Instead it is statistically significant to assume a reduced penetrance value of 0.96 . The absolute value of 0.96 may even be an overestimate owing to a bias towards the collection of affected persons in the ascertainment of Best's disease families. The definite proof that III.14 is a carrier of the Best's disease gene but is not expressing the disease will have to await the molecular characterisation of the mutation. However, our study strongly suggests that the clinical examination and, more importantly, the electro-oculogram (EOG) may not identify all carriers of the Best's disease gene. This may have important consequences for the genetic counselling of at risk persons.

This work was supported by grants from the Retinitis PigmenDeutsche Forschungsemeinsch (TFG (We 1259/1-1).

1 Best F. Über eine hereditäre Maculaaffection. Z Augenheilkd 1905;13:199-212.

2 Weingeist TA, Kobrin JL, Watzke RC. Histopathology of Best's macular dystrophy. Arch Ophthalmol 1982;100:1108-14.

3 Braley AE, Spivey BE. Hereditary vitelline macular degeneration: a clinical and functional evaluation of a new pedigree with variable expressivity and dominant inheritpedigree with variable expressivity and dom
ance. Arch Ophthalmol 1964;72:743-62.

4 Nordström S, Barkman Y. Hereditary macular degeneration (HMD) in 246 cases traced to one gene-source in
Central Sweden. Hereditas 1976;84:163-76.

5 Nordström S, Thorburn W. Dominantly inherited macular degeneration (Best's disease) in a homozygous father with degeneration (Best's disease) in a homozy
11 children. Clin Genet 1980;18:211-6.

6 Stone EM, Nichols BE, Streb LM, Kimura AE, Sheffield VC. Genetic linkage of vitelliform macular degeneration VC. Genetic linkage of vitelliform macular degeneration 1992;1:246-50. 
7 Deutman AF. Electro-oculography in families with vitelliform dystrophy of the fovea: detection

8 Weleber RG. Fast and slow oscillations of the electrooculogram in Best's macular dystrophy and retinitis pigmentosa. Arch Ophthalmol 1989;107:530-7.

9 Steinberg RH, Linsenmeier RA, Griff ER. Three lightevoked responses of the retinal pigment epithelium Vision Res 1983;23:1315-23.

10 Francois J, de Rouck A, Fernandez-Sasso D. Electrooculography in vitelliform degeneration of the macula. oculography in vitelliform degen
Arch Ophthalmol 1967;77:726-33.

11 Francois J, de Rouck A, Fernandez-Sasso D. Electroretinography and electro-oculography in diseases of the posterior pole of the eyes. Adv Ophthalmol 1969;21:132-63.

12 Forsman K, Graff C, Nordström S, et al. The gene fo Best's macular dystrophy is located at $11 \mathrm{q} 13$ in a Swedish Best's macular dystrophy is located
family. Clin Genet 1992;42:156-9.

13 Weber BHF, Walker D, Müller B, Mar L. Best's vitelliform dystrophy maps to proximal 11 q flanked by D11 9903 and dystrophy maps to proximal $11 \mathrm{q}$ flanked by D11S903 and press).

14 Marmor

4 Marmor MF. An international standard for electroretino-

15 Arden GB, Barrada A, Kelsey JH. New clinical test of retinal function based on the standing potential of the eye Br f Ophthalmol 1962;46:449-67.

16 Fishman GA. The electro-oculogram in retinal disorders In: Fishman GA, Sokol S, eds. Electrophysiologic testing in disorders of the retina, optic nerve, and visual pathway. American Academy of Ophthalmology, Ophthalmology Monographs No 2, 1990:91-102.

17 Kunkel LM, Smith KD, Boyer SH, et al. Analysis of human $\mathrm{Y}$ chromosome specific reiterated DNA in chromosome variants. Proc Natl Acad Sci USA 1977;74 1245-9.

18 Kaneshige $T$, Takagi $K$, Nakamura S, Hirasawa T, Sada $M$, Uchida $K$. Genetic analysis using fingernail DNA Nucleic Acids Res 1992;20:5489-90.

19 Weissenbach J, Gyapay G, Dib C, et al. A second- generation linkage map of the human genome. Nature 1992;359:794-801.

20 Hauge XY, Evans GA, Litt M. Dinucleotide repeat polymorphism at the D11S534 locus. Nucleic Acids Res 1991;19:4308.

21 Browne DL, Gault J, Thompson MB, Hauge XY, Evans GA, Litt $M$. Dinucleotide repeat polymorphism at the D11S527 locus. Nucleic Acids Res 1991;19:4790.

22 Polymeropoulos MH, Xiao H, Rath DS, Merril CR. Dinucleotide repeat polymorphism at the int-2 protooncogene locus (INT2). Nucleic Acids Res 1990;18:7468.

23 Iwasaki H, Stewart PW, Dilley WG, et al. A minisatellite and a microsatellite polymorphism within $1.5 \mathrm{~kb}$ at the human muscle glycogen phosphorylase (PYGM) locus can be amplified by PCR and have combined informativeness of PIC 0.95. Genomics 1992;13:7-15.

24 Lathrop GM, Lalouel JM, Julier C, Ott J. Strategies for multilocus linkage analysis in humans. Proc Natl Acad Sci multilocus linkage analysi

25 Krill AE, Morse PA, Potts AM, Klien BA. Hereditary vitelliruptive macular degeneration. Am $\mathscr{f}$ Ophthalmol 1966;61:1405-15.

26 Blanton SH, Heckenlively JR, Cottingham AW, et al. Linkage mapping of autosomal dominant retinitis pigmentosa (RP1) to the pericentric region of human chro-

27 Farrar JG, Kenna P, Jordan SA, et al. A three-base-pair deletion in the peripherin-RDS gene in one form of retinitis pigmentosa. Nature 1991;354:478-80.

28 Jordan SA, Farrar GJ, Kenna P, et al. Localization of an autosomal dominant retinitis pigmentosa gene to chromosome 7q. Nature Genet 1993;4:54-8.

29 Nichols BE, Sheffield VC, Vandenburgh K, Drack AV, Kimura AE, Stone EM. Butterfly-shaped pigment dystrophy of the fovea caused by point mutation in codon 167 of the RDS gene. Nature Genet 1993;3:202-7.

30 Wells J, Wroblewski J, Keen J, et al. Mutations in the human retinal degeneration slow (RDS) gene can cause either retinitis pigmentosa or muscular dystrophy. Nature Genet 1993;3:213-8. 